\title{
Comparison of the bleaching susceptibility of coral species by using minimal samples of live corals
}

\author{
Jih-Terng Wang ${ }^{1}$, Chi-Wei Chu ${ }^{1}$, Keryea Soong ${ }^{\text {Corresp. } 1}$ \\ ${ }^{1}$ Department of Oceanography, National Sun Yat-sen University, Kaohsiung, Taiwan \\ Corresponding Author: Keryea Soong \\ Email address: keryea@g-mail.nsysu.edu.tw
}

In massive bleaching events (losing symbiotic algae from corals), more sensitive corals are bleached earlier than other corals. To perform a comparison of bleaching susceptibility within and across coral species, a simple quantitative method is required. Accordingly, we present a laboratory-based method for comparing the bleaching susceptibility of various coral species by using a standardized image analysis protocol. Coral fragments were sampled from the colonies of 5 species selected from Kenting, southern Taiwan, and maintained in the same aquarium tank with circulating seawater; 2 seawater temperature regimes were used [i.e., fast-heating program (FHP), with a heating rate of 1 으 $\mathrm{C}$ per day; and slow-heating program (SHP), with a heating rate of 1 으 $\mathrm{C}$ per 3 days]. Each coral fragment was photographed periodically, and the colored images were subsequently converted to grayscale images and then digitally analyzed to determine the standardized grayscale values $\left(\mathrm{G}_{0}\right)$ by comparing with that of standard color strip. The $\mathrm{G}_{0}$ of a sample at each time of photographing during bleaching was divided by the difference of $\mathrm{G}_{0}$ between the acclimating and the same but completely bleached fragment to derive the relative grayscale (RG\%) at a particular stage of bleaching; this is done for each coral fragment of a colony. The smaller the RG\% of a coral fragment the closer it is approaching completely bleached condition. The level of decrease in RG\% within a time series of images in each heating regime was used to establish a bleaching time index (BTI). The lower the BTI, the sooner to reach a defined bleaching level (e.g., 30\%), this indicates the coral is more sensitive to thermal bleaching. In the experiment, we compared the bleaching susceptibility of the 5 species. Based on the proposed BTI, the 5 species were ranked in terms of bleaching susceptibility, and the rankings were identical between the 2 temperature regimes; 3 species in Pocilloporidae had lower BTI, whereas the hydrocoral Millepora species had the highest BTI. Within each heating regime, the BTI of different species were ranked and used to indicate susceptibility. In the FHP, the 3 Pocilloporidae species could be divided into 2 groups in terms of bleaching susceptibility. FHP not only 
displayed a higher differentiating capability on coal bleaching susceptibility than SHP, but also had a faster completion time, thus reducing the likelihood of unforeseen complications during the tank experiments. Our color-based method is easier and less effort-intensive than methods involving the assessment of zooxanthellae densities. Moreover, it requires much fewer replicates and all samples in one large tank (e.g., 300L) for the studies considering multiple species comparisons. This method opens opportunities for studying the effects of species types, acclimatization (e.g., seasons), and environmental factors other than temperature on coral bleaching. 
1 Comparison of the Bleaching Susceptibility of Coral Species by Using Minimal Samples of Live

2 Corals

3

4

5

6

7

8

\section{Jih-Terng Wang, Chi-Wei Chu, Keryea Soong}

Department of Oceanography, National Sun Yat-sen University, Kaohsiung, Taiwan

Corresponding Author:

Keryea Soong

Department of Oceanography, National Sun Yat-sen University, Kaohsiung, 80424, Taiwan

Email address: keryea@g-mail.nsysu.edu.tw

\section{Abstract}

In massive bleaching events (losing symbiotic algae from corals), more sensitive corals are bleached earlier than other corals. To perform a comparison of bleaching susceptibility within and across coral species, a simple quantitative method is required. Accordingly, we present a laboratory-based method for comparing the bleaching susceptibility of various coral species by using a standardized image analysis protocol. Coral fragments were sampled from the colonies of 5 species selected from Kenting, southern Taiwan, and maintained in the same aquarium tank with circulating seawater; 2 seawater temperature regimes were used [i.e., fast-heating program (FHP), with a heating rate of $1^{\circ} \mathrm{C}$ per day; and slow-heating program (SHP), with a heating rate of $1^{\circ} \mathrm{C}$ per 3 days]. Each coral fragment was photographed periodically, and the colored images were subsequently converted to grayscale images and then digitally analyzed to determine the standardized grayscale values $\left(\mathrm{G}_{0}\right)$ by comparing with that of standard color strip. The $\mathrm{G}_{0}$ of a sample at each time of photographing during bleaching was divided by the difference of $\mathrm{G}_{0}$ between the acclimating and the same but completely bleached fragment to derive the relative grayscale (RG\%) at a particular stage of bleaching; this is done for each coral fragment of a colony. The smaller the RG\% of a coral fragment the closer it is approaching completely bleached condition. The level of decrease in RG\% within a time series of images in each heating regime was used to establish a bleaching time index (BTI). The lower the BTI, the sooner to reach a defined bleaching level (e.g., 30\%), this indicates the coral is more sensitive to thermal bleaching. In the experiment, we compared the bleaching susceptibility of the 5 species. Based on the proposed BTI, the 5 species were ranked in terms of bleaching susceptibility, and the rankings were identical between the 2 temperature regimes; 3 species in Pocilloporidae had lower BTI, whereas the hydrocoral Millepora species had the highest BTI. Within each heating regime, the BTI of different species were ranked and used to indicate susceptibility. In the FHP, the 3 Pocilloporidae species could be divided into 2 groups in terms of bleaching susceptibility. FHP not only displayed a higher differentiating capability on coal bleaching susceptibility than SHP, but also had a faster completion time, thus reducing the likelihood of unforeseen 
41 complications during the tank experiments. Our color-based method is easier and less effort-

42

43

44

45

46

47

48

49

50

51

52

53

54

55

56

57

58

59

60

61

62

63

64

65

66

67

68

69

70

71

72

73

74

75

76

77

78

79

80

81

82

intensive than methods involving the assessment of zooxanthellae densities. Moreover, it requires much fewer replicates and all samples in one large tank (e.g., 300L) for the studies considering multiple species comparisons. This method opens opportunities for studying the effects of species types, acclimatization (e.g., seasons), and environmental factors other than temperature on coral bleaching.

\section{Introduction}

Coral bleaching is primarily caused by the breakdown of coral-algal symbiosis under heat stress; the expulsion of symbiotic algae from thin coral tissues reveals the white carbonate skeleton underneath (Fitt et al., 2001; Douglas, 2003; Lesser \& Farrell, 2004). In the context of global warming, the substantial spatial scale of coral bleaching with high mortality rates has caused a worldwide decline in coral coverage that has had a destructive impact on reef ecology (HoeghGuldberg et al., 2007; Jones et al., 2008). The increasing incidence of beyond-threshold seawater temperatures has increased the frequency of coral bleaching events such as that at the Great Barrier Reef in 2016 (Hughes et al., 2018). The large scale of coral bleaching highlights the catastrophic impact of global warming; this has thus stimulated considerable attention on the preservation of coral reefs.

Although the mechanisms underpinning coral bleaching are still not fully understood (reviewed in van Oppen \& Lough, 2018), numerous efforts have been devoted to explore the possibility of enhancing the capacity of corals to survive at higher (future) temperatures. Strategies proposed for improving coral resistance to thermal stress entail applying temperature acclimatization and adaptation measures (e.g., Bellantuono et al., 2012; Putnam \& Gates, 2015; Majerova et al., 2021), searching for heat-tolerant genotypes in natural or artificial hightemperature environments (e.g., Coles \& Riegl, 2012; Kao et al., 2018), applying probiotic microbe inoculation (Rosado et al., 2019), and using CRISPR/Cas9-editing techniques to mediate heat tolerance capability (Cleves et al., 2018). These strategies require examining the bleaching performance of corals in tank experiments under a temperature-increasing process to verify the thermal tolerability of the treated corals.

The rate of decrease in algal density in coral tissues is conventionally used as a measure to directly demonstrate the bleaching level of corals under thermal stress. Algal cell density, occasionally combined with chlorophyll $a$ content from corals (e.g., Hoegh-Guldberg \& Smith, 1989) or used along with a detailed measurement of photosynthetic processes and related physiological parameters (e.g., Jones et al., 1998; Fitt et al., 2001) enables monitoring the physiological condition of individual coral colonies under stress. However, deriving this measure necessitates specialized equipment and considerable effort, thus restricting the application of this approach. In addition to cell-counting methods, observer-based methods have been developed for field surveys of coral health through the use of color reference cards with multiple hues (Siebeck et al., 2006) or use of simple color reference strips supplemented with photographic images (Winters et al., 2009; Chow et al., 2016; Bryant et al., 2017). The feasibility and reliability of these methods have been confirmed using various approaches (e.g., Montano et al., 2010; Amid et al., 2018). Observer-based methods that rely on a subjective color-based assessment of corals

Peer) reviewing PDF | (2021:08:65149:2:0:NEW 21 Dec 2021) 
83 are quicker and less expensive than cell-counting methods but are potentially biased by the 84 personal judgements of assessors. Such bias, however, could be addressed by applying images 85 captured under a set of fixed conditions and then analyzing the images through computer 86 software. Photography-based methods have considerably improved the operational efficiency of 87 field surveys of coral bleaching events. Moreover, studies have demonstrated that image data 88 were highly correlated with measurements of the algal cell density and chlorophyll content of 89 corals, confirming the appropriateness of using image data to research bleaching conditions 90 (Winters et al., 2009; Chow et al., 2016; Bryant et al., 2017). However, studies have yet to apply 91 photography-based methods in tank experiments. Instead, they have generally applied cell92 counting methods to compare the bleaching susceptibility of corals with different acclimatization

93 94 95 96 97 98 99 histories or experimentally treated coral samples; such methods require a considerable quantity of living corals and more sophisticated handling efforts and procedures.

To fill this gap, the present study applied a photography-based method to distinguish coral bleaching under different conditions, such as different species and heating regimes, in a tank. We developed a bleaching time index (BTI), calculated from the changes in relative monotone grayscale of images with time, to compare coral bleaching susceptibility.

\section{Materials \& Methods}

A total of 5 species of corals from the shallow waters of Kenting, southern Taiwan (120 $41^{\prime} 43^{\prime \prime} \mathrm{E}$, $\left.21^{\circ} 59^{\prime} 5^{\prime \prime} \mathrm{N}\right)$, were collected by scuba divers. The collection permit for this investigation was issued by the Kenting National Park Authority of Taiwan to KS. Four scleractinian corals (Seriatopora caliendrum, Pocillopora verrucosa, Pocillopora damicornis, and Favites complanata) and one zooxanthellate hydrocoral (Millepora intricata) were included in this study. For each coral species, 5 colony replicates were selected, and 2 coral fragments $(4-8 \mathrm{~cm}$ per fragment) from each colony were harvested for the bleaching experiment. The species were transported to the laboratory and separated into 2 identical aquarium tanks, with each containing $300 \mathrm{~L}$ of seawater. Thus, each species contained 5 colony replications for each of 2 treatments, and the coral fragments of all 5 species were maintained in the same tank, for each temperature treatment.

Figure 1 illustrates the procedures of the study protocol. Specifically, the coral fragments harvested from all colonies of the 5 coral species were acclimatized at $27^{\circ} \mathrm{C}$ in one of the tanks for 1 week prior to the experiment. The seawater in the aquarium tank was first circulated horizontally by 2 underwater pumps - each of which provided a flow rate of 5,200 $\mathrm{L} \mathrm{h}^{-1}$ —and then filtered through several layers of aquarium filter pads using another pump (flow rate: 2,000 $\left.\mathrm{L} \mathrm{h}^{-1}\right)$. The corals were illuminated with photosynthetically active radiation $\left(25-30 \mu \mathrm{mol} \mathrm{m}{ }^{-2}\right.$ $\left.\mathrm{s}^{-1}\right)$ under a 12:12-h light-dark regime. Heating of seawater was conducted with 2 heaters $(500 \mathrm{w}$ for each) controlled by a digital thermostat (ISTA tsb-958), which were located right in front of an underwater pump to quickly mix water and away from tested corals. During the heat treatment, one of the tanks was used to implement a fast-heating program (FHP; temperature increment rate $=1{ }^{\circ} \mathrm{C}$ per day), and the other tank was used to implement a slow-heating program 
123 (SHP; temperature increment rate $=1{ }^{\circ} \mathrm{C}$ per 3 days). The temperature setting was changed at

124

125

126

127

128

129

130

131

132

133

134

135

136

137

138

139

140

141

142

143

144

145

146

147

148

149

150

151

152

153

154

155

156

157

158

159

160

noon each day, and approximately $1 \mathrm{~h}$ of heating was generally required to reach the target temperature. The water temperature was raised to $35^{\circ} \mathrm{C}$ and maintained at that level until the entire coral fragments were pale.

During the heat treatment, one image of all colony replicates of each of the 5 species was captured twice a day (at 6:00 AM and 6:00 PM) under a constant photographing condition. All images were captured by an Olympus Tough TG-5 camera (Olympus, Tokyo, Japan) with an attached LED ring light (Weefine, Guangdong, China), aperture speed of 1/50 s, ISO level of 100 , and aperture size of $\mathrm{f} / 2.8$; the camera was operated in macro mode, with the built-in camera flash turned off. The image acquisition process was completed when the coral fragments turned completely pale (i.e., no grayscale decreasing in 6 consecutive data points). All images were stored in JPG format for further bleaching level calculation.

The bleaching level of the coral fragments during the heat treatment was determined by deriving the changes in the relative grayscale values of a fixed square area in the images captured at every time point, as illustrated in Figure S1. Adobe Photoshop CC (2017) was used to measure the grayscale value in each target square area of coral sample $\left(G_{C}\right)$ and standard color strip $\left(G_{B}\right.$ for black and $\mathrm{G}_{\mathrm{W}}$ for white). Before measuring the grayscale of a selected area, the color image was firstly converted to grayscale, and then, that of the selected area was averaged with the Photoshop software. To correct for the variations in conditions between image acquisition sessions, the $G_{C}$ value derived for each image captured at each time point (6:00 AM and 6:00 PM) was first standardized with $G_{B}$ and $G_{W}$ to derive the standardized grayscale $\left(G_{0}\right)$, as presented in equation (1). A step-by-step procedure for estimating $\mathrm{G}_{0}$ was provided in Fig. S2. Subsequently, to measure color loss at each time point, the remaining color intensity, derived as $\mathrm{G}_{0}-\mathrm{G}_{0}^{\text {bleach }}$, was normalized with the total grayscale change $\left(\mathrm{G}_{0}^{\text {normal }}-\mathrm{G}_{0}^{\text {bleach }}\right)$ to derive the relative grayscale ( $\mathrm{RG} \%$ ) of a sample at each time point during bleaching, as presented in equation (2). $G_{0}^{\text {bleach }}$ represents the average $G_{0}$ of bleached coral fragments calculated from the images captured at the last 5 time points of heating experiment when the grayscale of coral fragment displays not further decrease; and $G_{0}^{\text {normal }}$ was derived from the mean of the first $5 G_{0}$ data points at $27^{\circ} \mathrm{C}$ incubation. All preceding calculations were conducted for each fragment of each species; that is, the calculations of relative changes were affected only by the performance of the coral fragment.

$$
\mathrm{G}_{0}=\left(\frac{\mathrm{G}_{\mathrm{C}}-\mathrm{G}_{\mathrm{W}}}{\mathrm{G}_{\mathrm{B}}-\mathrm{G}_{\mathrm{W}}}\right)
$$

$$
\mathrm{RG} \%=\frac{\mathrm{G}_{0}-\mathrm{G}_{0}^{\text {bleach }}}{\mathrm{G}_{0}^{\text {normal }}-\mathrm{G}_{0}^{\text {bleach }}} \times 100 \%
$$

The calculated $\mathrm{RG} \%$ values were plotted against incubation time and analyzed through curve fitting in SigmaPlot 14.1 software. The best-fitting regression analysis indicated a modified Gaussian regression model revealing the highest regression coefficient $\left(\mathrm{R}^{2}\right)$. Parameters and $\mathrm{R}^{2}$ values derived using the modified Gaussian equation for all 50 data sets are presented in Table $\mathrm{S} 1$; the $\mathrm{R}^{2}$ values ranged from 0.9326 to 0.9978 (mean $\left.\pm \mathrm{SD}=0.9856 \pm 0.0125\right)$. The

Peer) reviewing PDF | (2021:08:65149:2:0:NEW 21 Dec 2021) 
161

162

163

164

165

166

167

168

169

170

171

172

173

174

175

176

177

178

179

180

181

182

183

184

185

186

187

188

189

190

191

192

193

194

195

196

197

198

199

200

modified Gaussian regression equation was further used to estimate the time (in days) required for the grayscale to decrease during bleaching, and then applied to develop the BTI for evaluation of the bleaching rate and heat stress susceptibility of the various coral species. With the regression equation, SigmaPlot provided the corresponding $\mathrm{X}$ (incubation time point) and $\mathrm{Y}$ (RG\%) values within the range of input data, which were used to calculate the incubation time (in days) at which RG\% decreased by $10 \%, 20 \%, 30 \%, 40 \%$, or $50 \%$ through interpolation. Because $10 \%, 20 \%, 30 \%, 40 \%$, and $50 \%$ decreases in grayscale (color) values produced similar results in terms of the differentiation of bleaching susceptibility among the species, only results obtained at $10 \%, 30 \%$, and $50 \%$ are presented here (Fig. 4). We defined the time required to reduce the $\mathrm{RG} \%$ value of coral samples during the heat treatment as the BTI. BTI values were compared between the coral species by using one-way analysis of variance followed by Tukey's test for post-hoc analyses. The appropriateness of using BTI to evaluate bleaching susceptibility was also examined with an analysis by Pearson correlation coefficient between the treatments of FHP and SHP.

\section{Results}

When seawater was gradually heated to and maintained at $35^{\circ} \mathrm{C}$ in both the FHP $\left(1{ }^{\circ} \mathrm{C}\right.$ per day $)$ and SHP $\left(1^{\circ} \mathrm{C}\right.$ per 3 days), the bleaching responses of the coral fragments harvested from the colonies of the 5 coral species varied [Fig. 2(B-F), Fig. 3(B-F), and Fig. 4]. In Fig. 2 and 3, we considered a $5 \%$ decrease in relative grayscale as the criterion to calculate the BTI in order to determine the time at which initial bleaching occurred. Accordingly, we observed that in the FHP, coral bleaching started on day $3.2 \pm 0.3$ for $S$. caliendrum, day $5.5 \pm 0.4$ for $P$. verrucosa, day $6.4 \pm 1.1$ for $P$. damicornis, day $6.8 \pm 0.9$ for $F$. complanata, and day $8.4 \pm 0.8$ for $M$. intricata. In the SHP, the bleaching started on day $7.9 \pm 1.6$ for $S$. caliendrum, day $9.9 \pm 4.2$ for P. verrucosa, day $7.9 \pm 3.2$ for $P$. damicornis, day $12.2 \pm 2.6$ for $F$. complanata, and day $22.5 \pm$ 2.2 for $M$. intricata. Fig. 2(B-F) and 3(B-F) also showed higher within-species variations in the days of starting bleaching as treated by SHP (CV\%: 10.0\% 40.5\%) than by FHP (CV\%: $6.8 \%$ $\sim 17.2 \%)$ in the 5 testing coral species. Notably, the susceptibility rankings of the coral replicates were the same between the FHP and SHP.

In Fig. 2 and 3, the hydrocoral M. intricata also exhibited the highest tolerance to temperature increases compared with the other 4 scleractinian coral species; specifically, it exhibited the longest endurance before the initiation of bleaching, tolerated the highest temperature before the initiation of bleaching, and exhibited the slowest bleaching rate. In addition, $M$. intricata displayed on average $>40 \%$ increase in the relative grayscale before the coral started bleaching in the SHP, compared with $\leqq 10 \%$ in the FHP and in both FHP and SHP for the other scleractinian coral species (Table S2).

Further to compare the BTI at different levels, as shown in Fig. 4, the 5 tested coral species displayed significantly varied response to the two treatments $(\mathrm{P}<0.001$, see ANOVA results in Table S3). However, the rankings of bleaching resistance among species determined by $\mathrm{BTI}_{10 \%}, \mathrm{BTI}_{30 \%}$, and $\mathrm{BTI}_{50 \%}$ were identical in both heat treatment programs. A comparison of the 
201

202

203

204

205

206

207

208

209

210

211

212

213

214

215

216

217

218

219

220

221

222

223

224

225

226

227

228

229

230

231

232

233

234

235

236

237

238

239

240

95\% confidence intervals for the FHP and SHP (Fig. 4) revealed that 8 out of 10 possible species pairs could be significantly distinguished in terms of bleaching resistance in the FHP; however, only 6 of 10 pairs could be significantly separated in terms of bleaching resistance in the SHP. A higher BTI indicates a greater bleaching resistance. Hence, in the FHP, the 5 coral species could be ranked (in descending order) into 4 groups as follows according to their bleaching resistance: M. intricata $>F$. complanata $\geqq(P$. damicornis $=P$. verrucosa $)>S$. caliendrum [Fig. 4 (ACE)]. However, in the SHP, the species could be ranked (in descending order) into only 3 groups as follows according to their bleaching resistance: $M$. intricata $>F$. complanata $>(P$. damicornis $=$ P. verrucosa $=S$. caliendrum) [Fig. 4 (BDF)]. Furthermore, the bleaching performance of the 5 coral species treated in the FHP were also significantly correlated with those of the species treated in the SHP (Fig. 5). The Pearson correlation coefficients (r) for the BTI data between the SHP and FHP were 0.754 for $\mathrm{BTI}_{10 \%}(p<0.01), 0.895$ for $\mathrm{BTI}_{30 \%}(p<0.01)$, and 0.898 for $\mathrm{BTI}_{50 \%}(p<0.01)$.

The variation of BTI method was further examined with the coefficients of variation (CV\%) of BTI values derived from colony replicates of each species. As indicated in Table S4, the $\mathrm{CV} \%$ levels of the BTI values at the $10 \%, 20 \%, 30 \%, 40 \%$, and $50 \%$ cutoff levels were low in all the tested coral species treated by the FHP (mean $\pm \mathrm{SD}=8.3 \% \pm 3.7 \% ; n=25)$ and 2 less sensitive species, namely $F$. complanata and M. intricata, by SHP $(9.3 \% \pm 4.0 \% ; n=10)$, but high in 3 thermal-sensitive species, namely $S$. caliendrum, $P$. verrucosa, and $P$. damicornis, by the SHP $(24.7 \% \pm 10.1 \% ; n=15)$. In summary, the results indicated that SHP would result in higher within-species variation in the BTI method when applied to heat sensitive coral species.

\section{Discussion}

This study proposes a color-based protocol that entails the use of the BTI to evaluate coral bleaching susceptibility in tanks. The BTI is calculated from the changes in the relative grayscale values of a selected area in images of corals. In this study, the $\mathrm{BTI}_{10 \%}, \mathrm{BTI}_{30 \%}$, and $\mathrm{BTI}_{50 \%}$ values [Fig. 4 (A, C, E)] obtained in the FHP could be used to rank the 5 coral species into 4 groups of bleaching susceptibility. In contrast to the rankings observed in the FHP, the species treated in the SHP could be ranked into only 3 groups according to their bleaching susceptibility [Fig. 4 (B, $\mathrm{D}, \mathrm{F})$ ]. Though the rankings were consistent between the SHP and FHP, slow heating rate did not increase resolution in differentiating bleaching susceptibility between the coral species.

Consistent ranking between the SHP and FHP demonstrated that the proposed BTI can be a fair tool used to assess natural processes. Besides that, monitoring bleaching process by the SHP displayed 2 features different from that by FHP. First, SHP resulted in higher within-species variations in estimating BTI values of 3 heat sensitive species, $S$. caliendrum, $P$. verrucosa, and P. damicornis than FHP did (Table S4). Within species, different susceptibility levels may be caused by both genetic and/or local environmental factors, which might be only observed by SHP. However, to the heat sensitive species, the likelihood of unforeseen complications occurring in tank experiment also can't be ruled out due to longer incubation time in tank 
241 condition. Second, to heat resistant species, like hydrocoral M. intricata in this study, there was a 242 higher percentage of increase in relative grayscale in the SHP ( $40 \%$ in average) than in the FHP 243 (10\% in average) before it declined relative grayscale below $100 \%$ (Fig. $2 \mathrm{~F}$ and 3F, Table S2).

244 The increases in relative grayscale in the initial period of bleaching trials might be due to the 245 accumulation of expelled symbiotic algae in the topical area of coral tissue. The high initial rise 246 of RG\% of $M$. intricata might be partly attributable to their heat resistant nature resulting in a 247 slower mode of symbiotic algae releasing, and partly to their porous skeleton which made the 248 releasing of symbiotic algae more slowly.

Based on our results, the FHP are superior to the SHP in comparing the bleaching

250

251

252

253

254

255

256

257

258

259

260

261

262

263

264

265

266

267

268

269

270

271

272

273

274

275

276

277

278

279

280

susceptibility coral species. Nevertheless, it remains to be tested whether the BTI could also produce the same rankings for species subjected to other methods of bleaching induction. The possible effects of zooxanthellae, feeding, and light can also be tested under laboratory conditions using this method.

The bleaching susceptibility levels of the scleractinian coral species observed in this study using the proposed BTI are comparable to those reported by previous studies (e.g., Loya et al., 2001; Keshavmurthy et al., 2014); however, the results observed for the branching hydrocoral coral M. intricata are not comparable to those in the literature. Previous studies conducting field surveys have indicated that Millepora species are thermally sensitive (Loya et al., 2001; Dias et al. 2016; Teixeira et al., 2019; Duarte et al., 2020), but we discovered that $M$. intricata was the most thermally resistant species in this study. This conflict might be derived from two possibilities, method bias and/or the other biological variations. The essential difference between BTI method and field survey on M. intricata is that the former provided timeseries quantitative observations of the same coral fragments and that the bleaching was relative to the acclimation periods. On the contrary, the evidence of heat sensitive in Millepora coral was all based on visual observation during field surveys. Field survey data have been limited to snapshots of multiple species taken at the same time; the assessments of bleaching were qualitative, although many colonies were selected for sampling. Of course, we cannot exclude other biological factors that might affect coral bleaching susceptibility, such as thermal sensitivity of algal symbionts (Sampayo et al., 2008; Stat et al., 2011; Howells et al., 2012; Hsu et al., 2012; Silverstein et al., 2012; Keshavmurthy et al. 2014), tissue thickness and stress enzyme activities of the coral host (Loya et al., 2001; Fitt et al., 2009; Wang et al. 2019), with or without probiotic microbes association (Rosado et al., 2019 and the references therein), and life histories with or without acclimatization or adaptation to higher temperature (Howells et al., 2016; DeCarlo et al., 2019; Wang et al., 2019; Barott et al., 2021). More studies are required to clarify the effects of these factors, and we suggest the methods developed here is more effective and efficient.

Imaging methods have several advantages over commonly used cell-counting methods (Table 1). First, imaging methods do not require sacrificing coral samples for cell counting; therefore, increasing sampling intervals does not require proportionally increasing the number of coral fragment samples, as is the case in cell-counting methods. For example, if our experiment

Peer) reviewing PDF | (2021:08:65149:2:0:NEW 21 Dec 2021) 
281

282

283

284

285

286

287

288

289

290

291

292

293

294

295

296

297

298

299

300

301

302

303

304

305

306

307

308

309

310

311

312

313

314

315

316

317

318

319

320

had been conducted using a cell-counting method, 60 times of replicate of coral fragments (i.e., 300) would have been required for each species to generate the same number of observations.

Second, due to much smaller sample sizes required for a species, many species could be accommodated in one tank. This effectively avoided the tank effect, which we are not really interested any way, and also reduced the potential complication of pseudo-replication in experimental design (Cornwall \& Hurd, 2016).

Third, imaging methods have lower technological requirements and are less labor intensive than cell-counting methods. Unlike an underwater imaging method used a decade ago (Winter et al., 2009), current imaging approaches are easier with the increased availability of automatically controlled underwater cameras, such as that used in this study. Furthermore, compared with labor-intensive cell-counting methods, imaging methods provide additional data points at low marginal costs.

Fourth, imaging methods provide a lower level of data bias than do cell-counting methods when used for intertaxa comparisons of bleaching performance under the same controlled conditions. Cell-counting methods usually underestimate algal densities in coral species with porous skeletons, such as Millepora spp.; in such species, complete recovery of algal cells from coral specimens by using methods commonly applied to scleractinian corals (e.g., water-pik or air brush; Edmunds, 1999) is almost impractical. By contrast, the imaging method used in this study derived only monotone (or grayscale) color changes during the bleaching process, which can provide the same observation of this process as the naked eyes. Although the colors of noncoral backgrounds (e.g., that of endolithic algae or the supporting materials for coral fixation) may distort the actual grayscale levels of coral samples in an image, such backgrounds can be removed from the images during the calculation of relative grayscale values within a sample. Therefore, our protocol affords more freedom in the selection of a region of interest in an image for calculating grayscale values, which reduces the number of coral fragment replication points to one. This is an advantage over the protocol proposed by Chow et al. (2016), in which more than 100 coral fragment areas are required for calculating grayscale values.

Imaging methods, nevertheless, have disadvantages in the monitoring of coral bleaching because they require a series of images, including images of the normal and the bleached stages of corals. Consequently, imaging methods are not suitable for directly assessing bleaching conditions in nature. Also, converting JPG image into grayscale is a nonlinear compression process, which might affect greyscale quantification. However, according to our results, this defect might only have minor impact on the final comparisons.

\section{Conclusions}

In summary, we developed a BTI for comparing the bleaching susceptibility of corals based on imaging method. The method used coral fragments efficiently and the small numbers of fragments themselves allow multiple species comparisons in the same tanks. This characteristic enable investigations of a wide variety of factors causing coral bleaching in the laboratory. 


\section{Acknowledgements}

323

324

325

326

327

328

329

330

331

332

333

334

335

336

337

338

339

340

341

342

343

344

345

346

347

348

349

350

351

352

353

354

355

356

357

358

359

360

We thank Te-Yu Chen, Chung-Wei Yang and Shannon Huang for assisting with the field and lab work, and Prof. Allen CA Chen for the identification of coral species. We also like to thank Paul Hussain and Yankuba Sanyang from Wallace Academic Editing for their assistance in English editing. Dr. Edson Vieira and another two anonymous reviewers provided many valuable comments and suggestion, which are greatly appreciated.

\section{References}

Amid C, Olstedt M, Gunnarsson JS, LeLan H, TranThiMinh H, VandenBrink PJ, Hellström M, Tedengren M (2018) Additive effects of the herbicide glyphosate and elevated temperature on the branched coral Acropora formosa in Nha Trang, Vietnam. Environ. Sci. Pollut. Res. 25: 13360-13372.

Barott KL, Huffmyer AS, Davidson JM, Lenz EA, Matsuda SB, Hancock JR, Innis T, Drury C, Putnam HM, Gates RD (2021) Coral bleaching response is unaltered following acclimatization to reefs with distinct environmental conditions. Proc Natl Acad Sci U S A 118: e2025435118.

Bellantuono AJ, Hoegh-Guldberg O, Rodriguez-Lanetty M (2012) Resistance to thermal stress in corals without changes in symbiont composition. Proc R Soc B Biol Sci 279: 1100-1107.

Bryant DEP, Rodriguez-Ramirez A, Phinn S, M. González-Rivero, Brown KT, Neal BP, HoeghGuldberg O, Dove S (2017) Comparison of two photographic methodologies for collecting and analyzing the condition of coral reef ecosystems. Ecosphere 8(10): e01971.

Chow MH, Tsang RHL, Lam EKY, Ang Jr. P (2016) Quantifying the degree of coral bleaching using digital photographic technique. J Exp Mar Biol Ecol 479: 60-68.

Cleves PA, Strader ME, Bay LK, Pringle JR, Matz MV (2018) CRISPR/Cas9-mediated genome editing in a reef-building coral. Proc Natl Acad Sci U S A 115:5235-5240.

Coles SL, Riegl BM (2012) Thermal tolerances of reef corals in the Gulf: a review of the potential for increasing coral survival and adaptation to climate change through assisted translocation. Mar Pollut Bull 72: 323-32.

Cornwall, CE, Hurd, CL (2016) Experimental design in ocean acidification research: problems and solutions. ICES J Mar Sci 73: 572-581.

Dias TLP, Gondim AI (2016) Bleaching in scleractinians, hydrocorals, and octocorals during thermal stress in a northeastern Brazilian reef. Mar Biodiv 46: 303-307.

DeCarlo TM, Harrison HB, Gajdzik L, Alaguarda D, Rodolfo-Metalpa R, D’Olivo J, Liu G, Patalwala D, McCulloch MT (2019) Acclimatization of massive reef-building corals to consecutive heatwaves. Proc. R. Soc. B 286: 20190235.

Douglas AE (2003) Coral bleaching — how and why? Mar Pollut Bull 46: 385-392.

Duarte GAS, Villela HDM, Deocleciano M, Silva D, Barno A, Cardoso PM, Vilela CLS, Rosado P, Messias CSMA, Chacon MA, Santoro EP, Olmedo DB, Szpilman M, Rocha LA, Sweet M 
361

362

363

364

365

366

367

368

369

370

371

372

373

374

375

376

377

378

379

380

381

382

383

384

385

386

387

388

389

390

391

392

393

394

395

396

397

398

399

and Peixoto RS (2020) Heat waves are a major threat to turbid coral reefs in Brazil. Front Mar Sci 7: 179.

Edmunds PJ (1999) The role of colony morphology and substratum inclination in the success of Millepora alcicornis on shallow coral reefs. Coral Reefs 18:133-140.

Fitt WK, Brown BE, Warner ME, Dunne RP (2001) Coral bleaching: interpretation of thermal tolerance limits and thermal thresholds in tropical corals. Coral Reefs 20:51-65.

Fitt WK, Gates RD, Hoegh-Guldberg O, Bythell JC, Jatkar A, Grottoli AG, Gomez M, Fisher P, Lajuenesse TC, Pantos O, Iglesias-Prieto R, Franklin DJ, Rodrigues LJ, Torregiani JM, van Woesik R, Lesser M (2009) Response of two species of Indo Pacific corals, Porites cylindrica and Stylophora pistillata, to short-term thermal stress: the host does matter in determining the tolerance of corals to bleaching. J Exp Mar Biol Ecol 373: 102-110.

Hsu C-M, Keshavmurthy S, Denis V, Kuo C-Y, Wang J-T, Meng P-J, Chen CA (2012)

Temporal and spatial variations in symbiont communities of catch bowl coral Isopora palifera (Scleractinia: Acroporidae) on Reefs in Kenting National Park, Taiwan. Zool Stud 51: 13431353.

Hoegh-Guldberg O, Smith GJ (1989) The effect of sudden changes in temperature, light and salinity on the population-density and export of zooxanthellae from the reef corals Stylophora Pistillata Esper and Seriatopora Hystrix Dana. J Exp Mar Biol Ecol 129: 279-303.

Hoegh-Guldberg O, Mumby PJ, Hooten AJ, Steneck RS, Greenfield P, Gomez E, Harvell CD, Sale PF, Edwards AJ, Caldeira K, Knowlton N, Eakin CM, Iglesias-Prieto R, Muthiga N, Bradbury RH, Dubi A, Hatziolos ME (2007) Coral reefs under rapid climate change and ocean acidification. Science 318:1737-1742

Howells EJ, Beltran VH, Larsen NW, Bay LK, Willis BL, van Oppen MJH (2012) Coral thermal tolerance shaped by local adaptation of photosymbionts. Nat Clim Change 2: 116-120.

Howells E J, Abrego D, Meyer E, Kirk NL, Burt JA (2016) Host adaptation and unexpected symbiont partners enable reef-building corals to tolerate extreme temperatures. Glob. Chang. Biol. 22: 2702-2714.

Hughes TP, Kerry JT, Baird AH, Connolly SR, Dietzel A, Eakin CM, Heron SF, Hoey AS, Hoogenboom MO, Liu G, McWilliam MJ, Pears RJ, Pratchett MS, Skirving WJ, Stella JS, Torda G (2018) Global warming transforms coral reef assemblages. Nature 556: 492-496.

Jones RJ, Hoegh-Guldberg O, Larkum AWD, Schreiber U (1998) Temperature-induced bleaching of corals begins with impairment of the $\mathrm{CO}_{2}$ fixation mechanism in zooxanthellae. Plant Cell Environ 21:1219-1230.

Jones AM, Berkelmans R, van Oppen MJH, Mieog JC, Sinclair W (2008) A community change in the algal endosymbionts of a scleractinian coral following a natural bleaching event: field evidence of acclimatization. Proc R Soc Ser B 275: 1359-1365.

Kao KW, Keshavmurthy S, Tsao CH, Wang JT, Chen CA (2018) Repeated and prolonged temperature anomalies negate Symbiodiniaceae genera shuffling in the coral Platygyra verweyi (Scleractinia; Merulinidae). Zool Stud. 2018;57: e55.

Peer) reviewing PDF | (2021:08:65149:2:0:NEW 21 Dec 2021) 
400 Keshavmurthy S, Meng P-J, Wang J-T, Kuo CY, Yang SY, Hsu CM, Gan CH, Dai CF, Chen CA

401

402

403

404

405

406

407

408

409

410

411

412

413

414

415

416

417

418

419

420

421

422

423

424

425

426

427

428

429

430

431

432

433

434

435

436

437

438 (2014) Can resistant coral-Symbiodinium associations enable coral communities to survive climate change? A study of a site exposed to long-term hot water input. PeerJ 2: e327.

Lesser MP, Farrell JH (2004) Exposure to solar radiation increases damage to both host tissues and algal symbionts of corals during thermal stress. Coral Reefs 23: 367-377.

Loya Y, Sakai K, Yamazato K, Nakano Y, Sambali H, van Woesik R (2001) Coral bleaching: the winners and the losers. Ecol Lett 4: 122-131.

Majerova E, Carey FC, Drury C, Gates RD (2021) Preconditioning improves bleaching tolerance in the reef-building coral Pocillopora acuta through modulations in the programmed cell death pathways. Mol Ecol doi: 10.1111/mec.15988.

Montano S, Seveso D, Galli P, Obura DO (2010) Assessing coral bleaching and recovery with a colour reference card in Watamu Marine Park, Kenya. Hydrobiologia 655: 99-108.

Putnam HM, Gates RD (2015) Preconditioning in the reef-building coral Pocillopora damicornis and the potential for trans-generational acclimatization in coral larvae under future climate change conditions. J Exp Biol 218: 2365-2372.

Rosado PM, Leite1 DCA, Duarte GAS, Chaloub RM, Jospin G, da Rocha UN, Saraiva JP, DiniAndreote F, Eisen JA, Bourne DG, Peixoto RS (2019) Marine probiotics: increasing coral resistance to bleaching through microbiome manipulation. ISME J 13: 921-936.

Sampayo EM, Ridgeway T, Bongaerts P, Hoegh-Guldberg O (2008) Bleaching susceptibility and mortality of corals are determined by fine-scale differences in symbiont type. Proc Natl Acad Sci U S A 105:10444-10449.

Siebeck UE, Marshall NJ, Kluter A, Hoegh-Guldberg O (2006) Monitoring coral bleaching using a colour reference card. Coral Reefs 25: 453-460.

Silverstein RN, Correa AMS, Baker AC (2012) Specificity is rarely absolute in coral-algal symbiosis: implications for coral response to climate change. Proc R Soc Lond B 279: 26092618.

Stat M, Gates RD (2011) Clade D Symbiodinium in scleractinian corals: a "nugget" of hope, a selfish opportunist, an ominous sign, or all of the above? J Mar Biol Article ID 730715.

Teixeira CD, Leitão RLL, Ribeiro FV, Moraes FC, Neves LM, Bastos AC, Pereira-Filho GH, Kampel M, Salomon PS, Sá JA, Falsarella LN, Amario M, Abieri ML, Pereira RC, Amado-Filho GM, Moura RL (2019). Sustained mass coral bleaching (2016-2017) in Brazilian turbid-zone reefs: taxonomic, cross-shelf and habitat-related trends. Coral Reefs 38: 801-813.

van Oppen M.J.H., Lough J.M. (2018) Synthesis: Coral Bleaching: Patterns, Processes, Causes and Consequences. In: van Oppen M., Lough J. (eds) Coral Bleaching. Ecological Studies (Analysis and Synthesis), vol 233. Springer, Cham.

Wang J-T, Wang Y-T, Keshavmurthy S, Meng P-J, Chen CA (2019) The coral Platygyra verweyi exhibits local adaptation to long-term thermal stress through host-specific physiological and enzymatic response. Sci. Rep. 9: 13492. 
439 Winters G, Holzman R, Blekhman A, Beer S, Loya Y (2009) Photographic assessment of coral 440 chlorophyll contents: implications for ecophysiological studies and coral monitoring. J. Exp. 441 Mar. Biol. Ecol. 380: 25-35.

442 
Figure 1

Outline of the study procedure for determining bleaching time index (BTI) of corals through image analysis. 


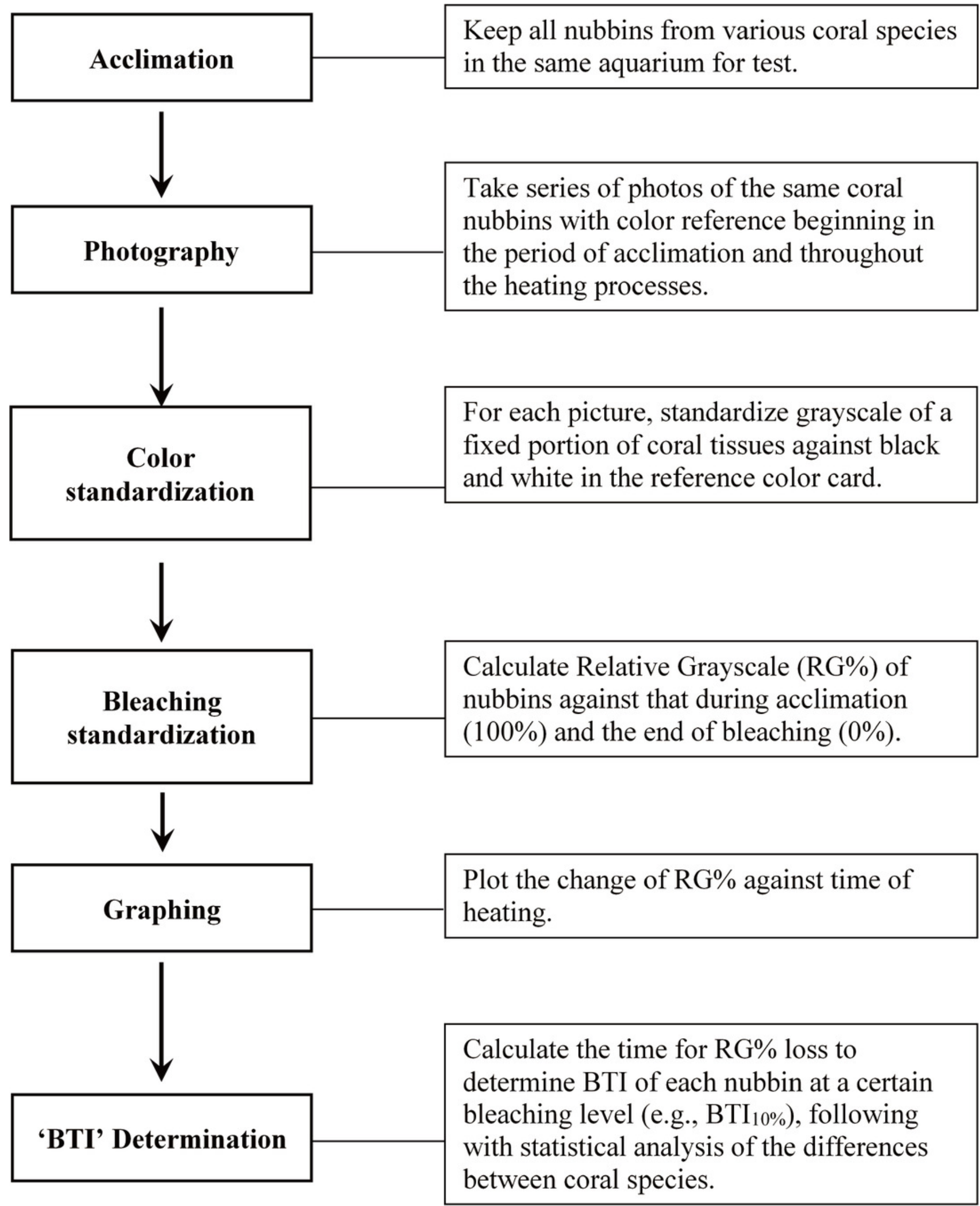




\section{Figure 2}

Bleaching responses of corals in the fast-heating program (FHP, $1^{\circ} \mathrm{C}$ per day).

(A) Temperature increment program, in which the seawater temperature was increased at a rate of $1^{\circ} \mathrm{C}$ per day from $27^{\circ} \mathrm{C}$ to $35^{\circ} \mathrm{C}$ and maintained at $35^{\circ} \mathrm{C}$ until the end of the experiment. (B) Seriatopora caliendrum, (C) Pocillopora verrucosa, (D) Pocillopora damicornis, (E) Favites complanata, and (F) Millepora intricata treated in one 300-L aquarium tank. Five color symbols represent coral fragments from different colonies. 


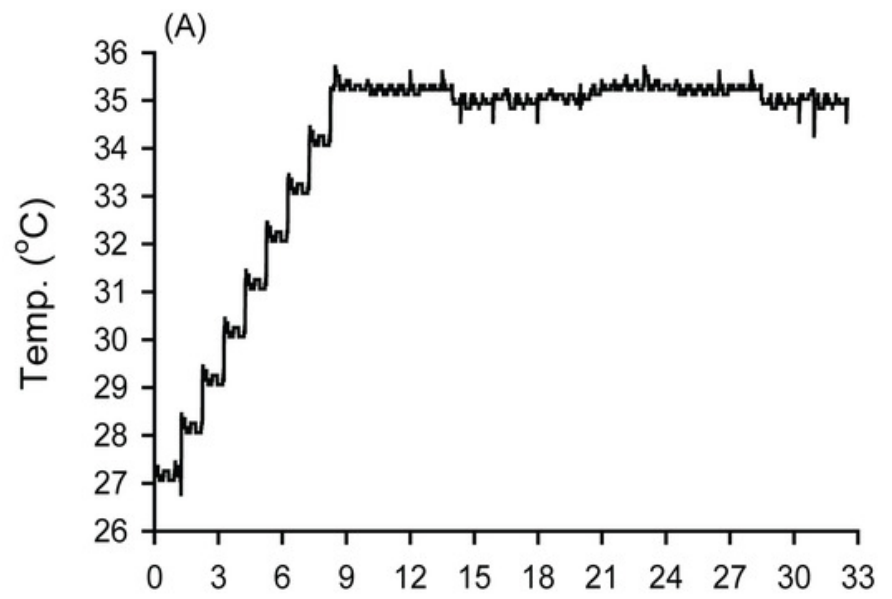

(B) S. caliendrum
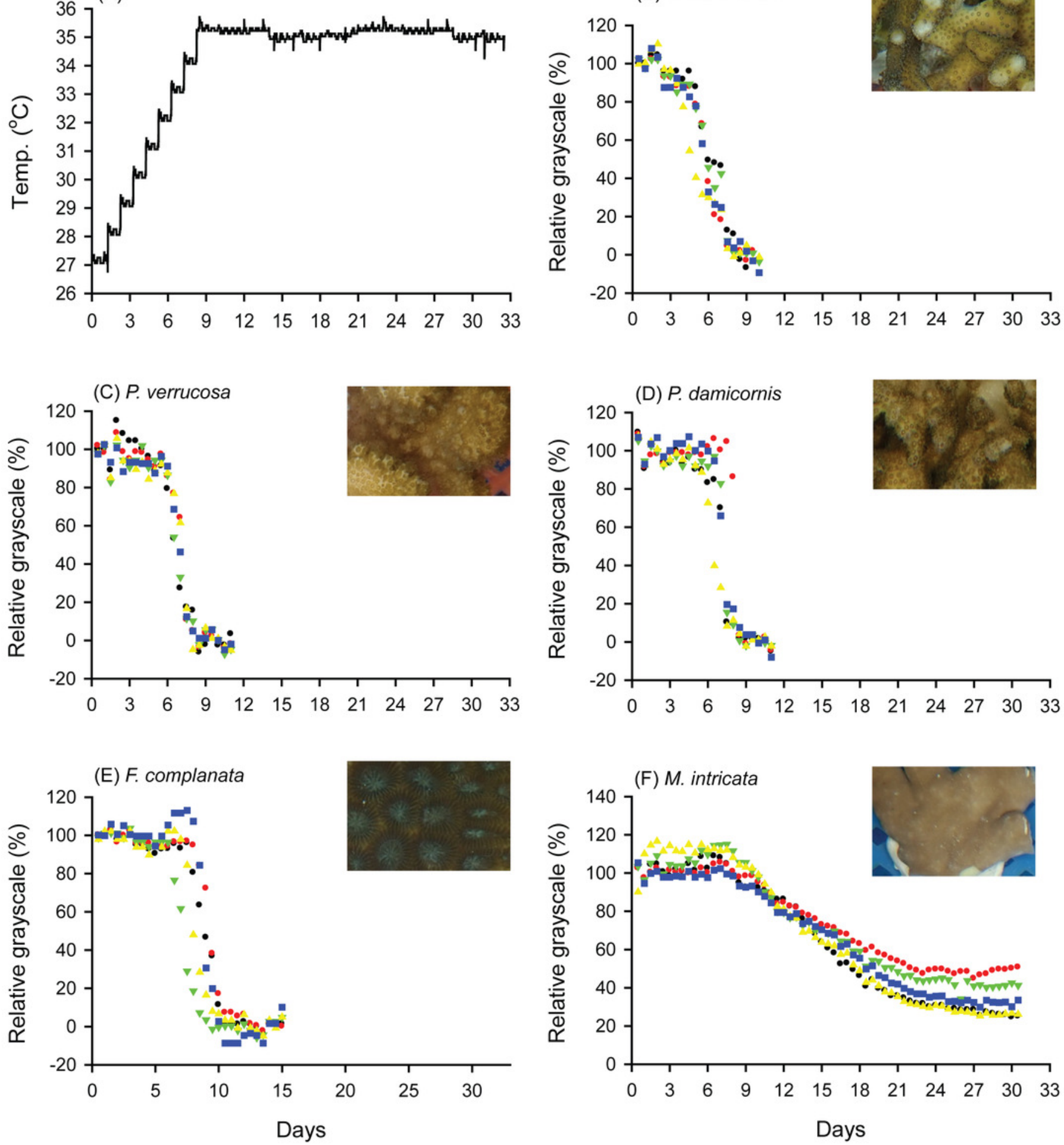


\section{Figure 3}

Bleaching responses of corals in the slow-heating program (SHP, $1^{\circ} \mathrm{C}$ per 3 days).

(A) Temperature increment program, in which the seawater temperature was increased, after 3 days of acclimation, at a rate of $1^{\circ} \mathrm{C}$ from $27^{\circ} \mathrm{C}$ to $35^{\circ} \mathrm{C}$ and maintained at $35^{\circ} \mathrm{C}$ until the end of the experiment. (B) Seriatopora caliendrum, (C) Pocillopora verrucosa, (D) Pocillopora damicornis, (E) Favites complanata, and (F) Millepora intricata treated in one 300-L aquarium tank. Five color symbols represent the coral fragments from different colonies. 


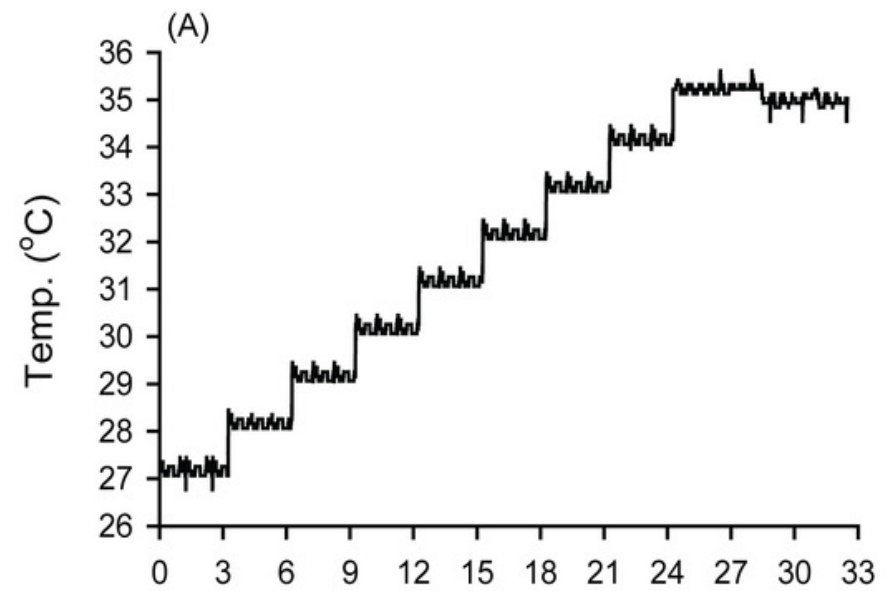

(B) S. caliendrum

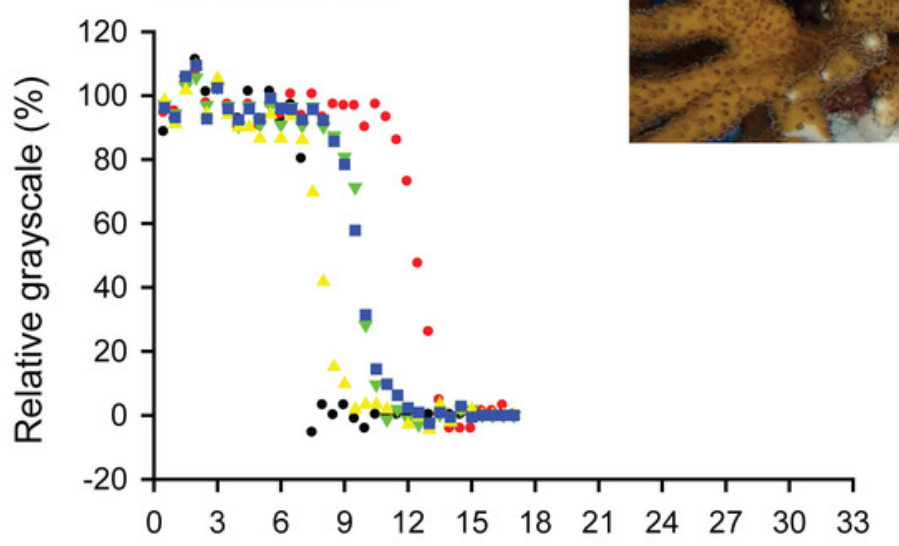

(C) P. verrucosa
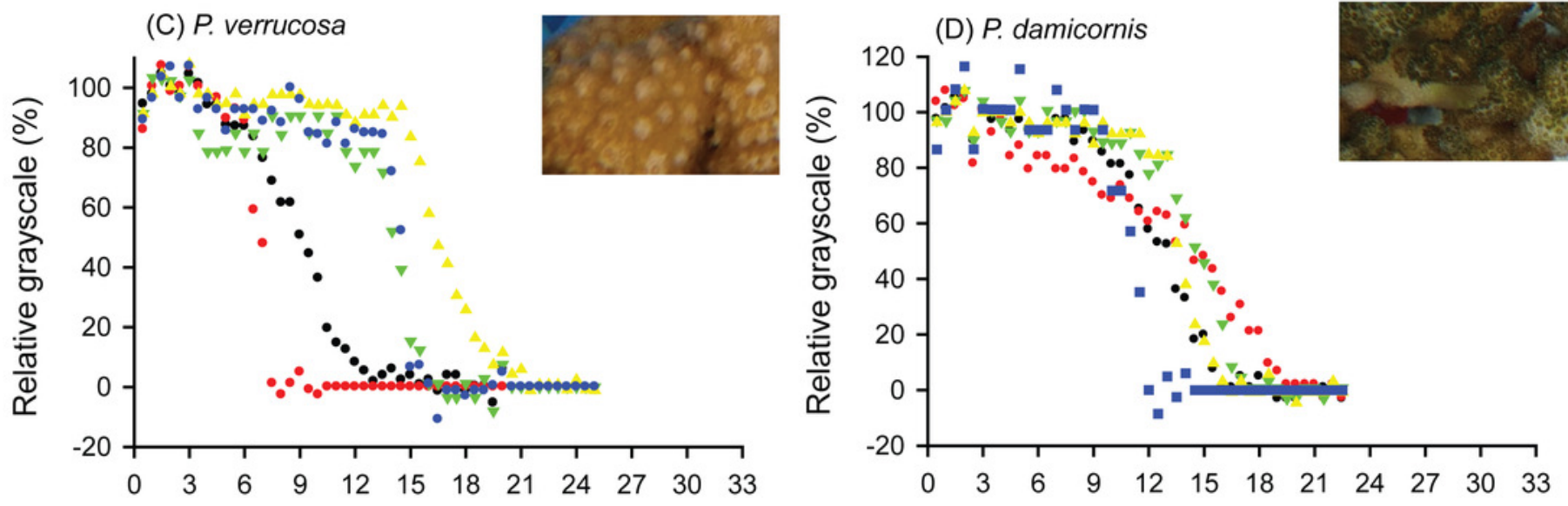

(E) F. complanata
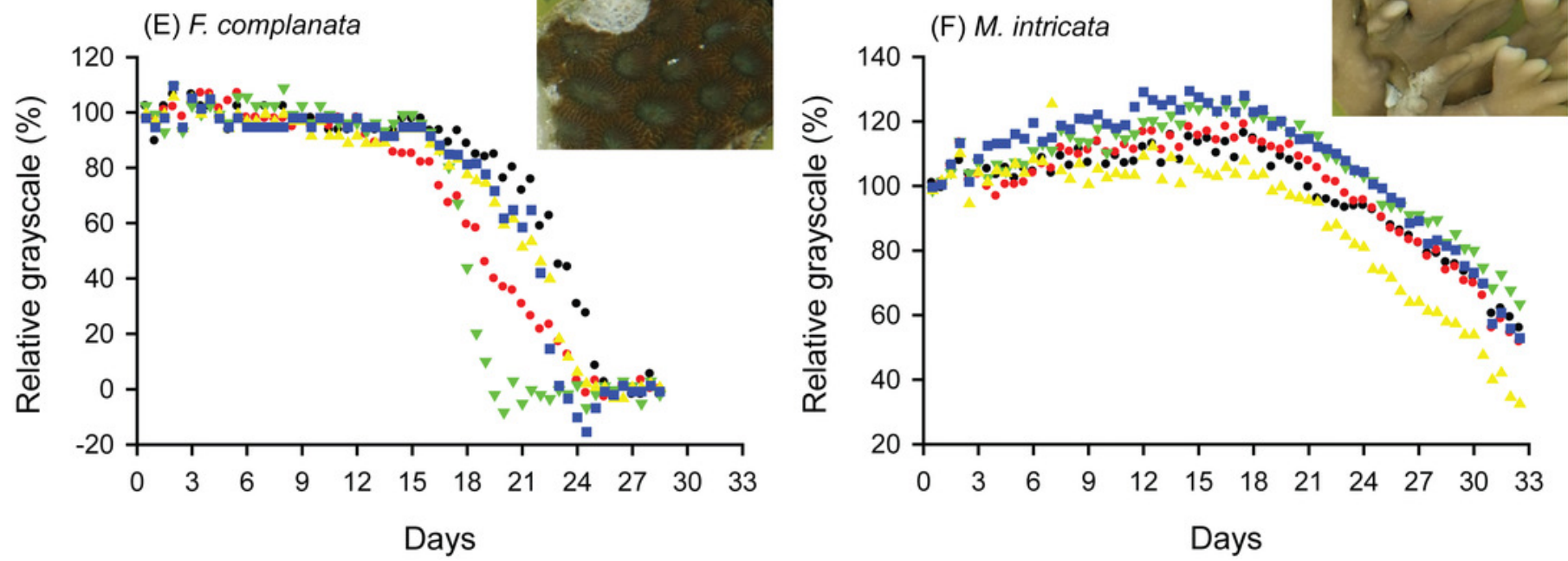


\section{Figure 4}

Bleaching time index (BTI) values calculated for the 5 coral species in the fast-heating program (FHP) and slow-heating program (SHP).

The decrease in the relative grayscale for calculating $B T I$ at the cutoff values of $10 \%(A B)$, $30 \%(C D)$ and $50 \%$ (EF) was derived from the data $(n=5)$ in Fig. 2 (FHP) and 3 (SHP). Whisker caps: the highest and lowest values; box: 95\% confidence intervals; black line: medium; red line: mean. Boxes labeled with the same letter are not significantly different at $p=0.05$ (Tukey's post hoc analysis, $\mathrm{n}=5$ ). Sc: Seriatopora caliendrum; Pv: Pocillopora verrucosa; Pd: Pocillopora damicornis; Fc: Favites complanata, Mi: Millepora intricata. 

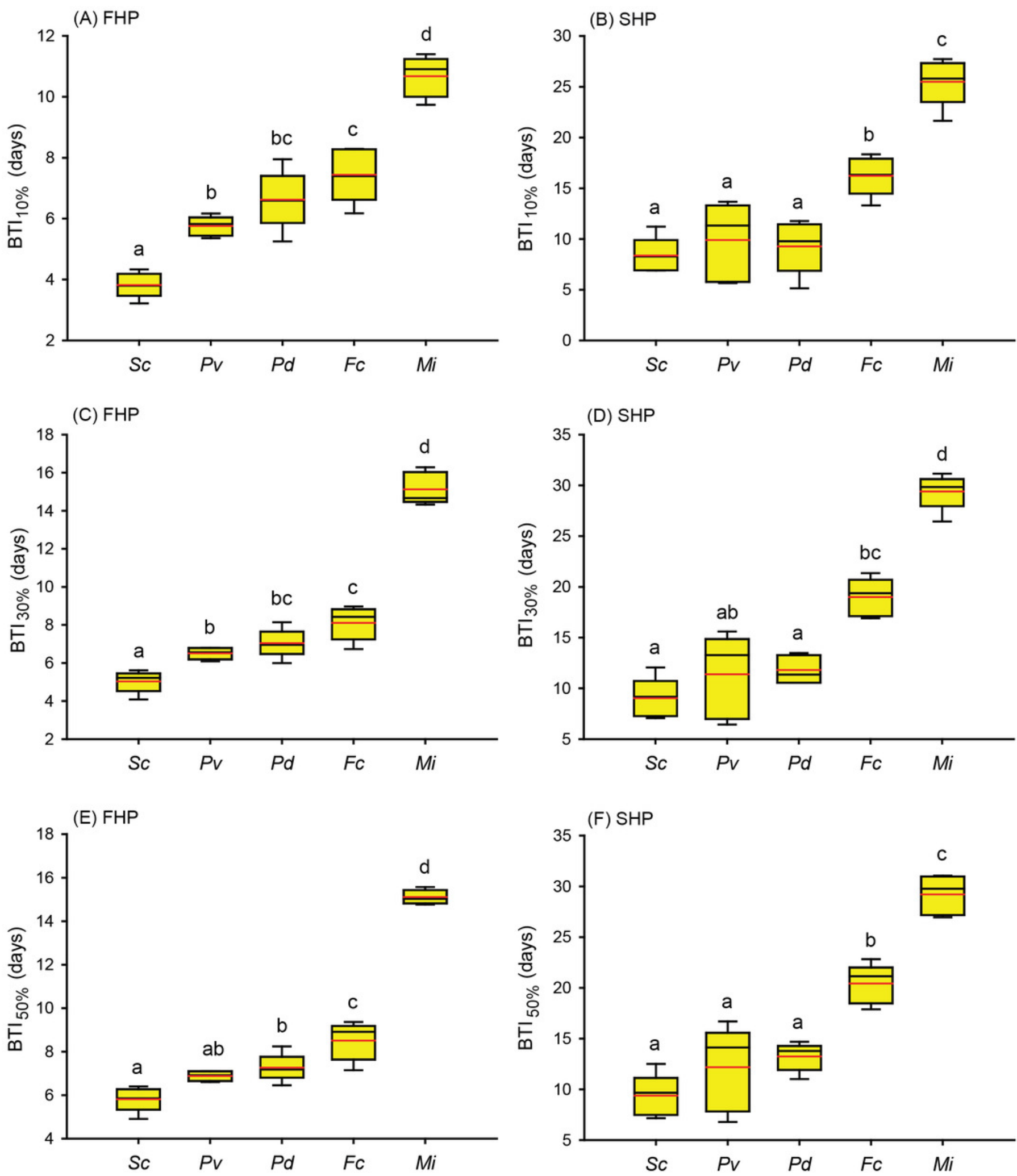
Figure 5

An example plot of the correlation between BTI obtained in the slow-heating program (SHP) and fast-heating program (FHP).

This example plot was derived from the results of $\mathrm{BTI}_{30 \%}$. Pearson correlation coefficient $=$ $0.90(p<0.01)$

- S. caliendrum $\bullet$ P. verrucosa $\nabla$. damicornis $\triangle F$. complanata $\square$. intricata

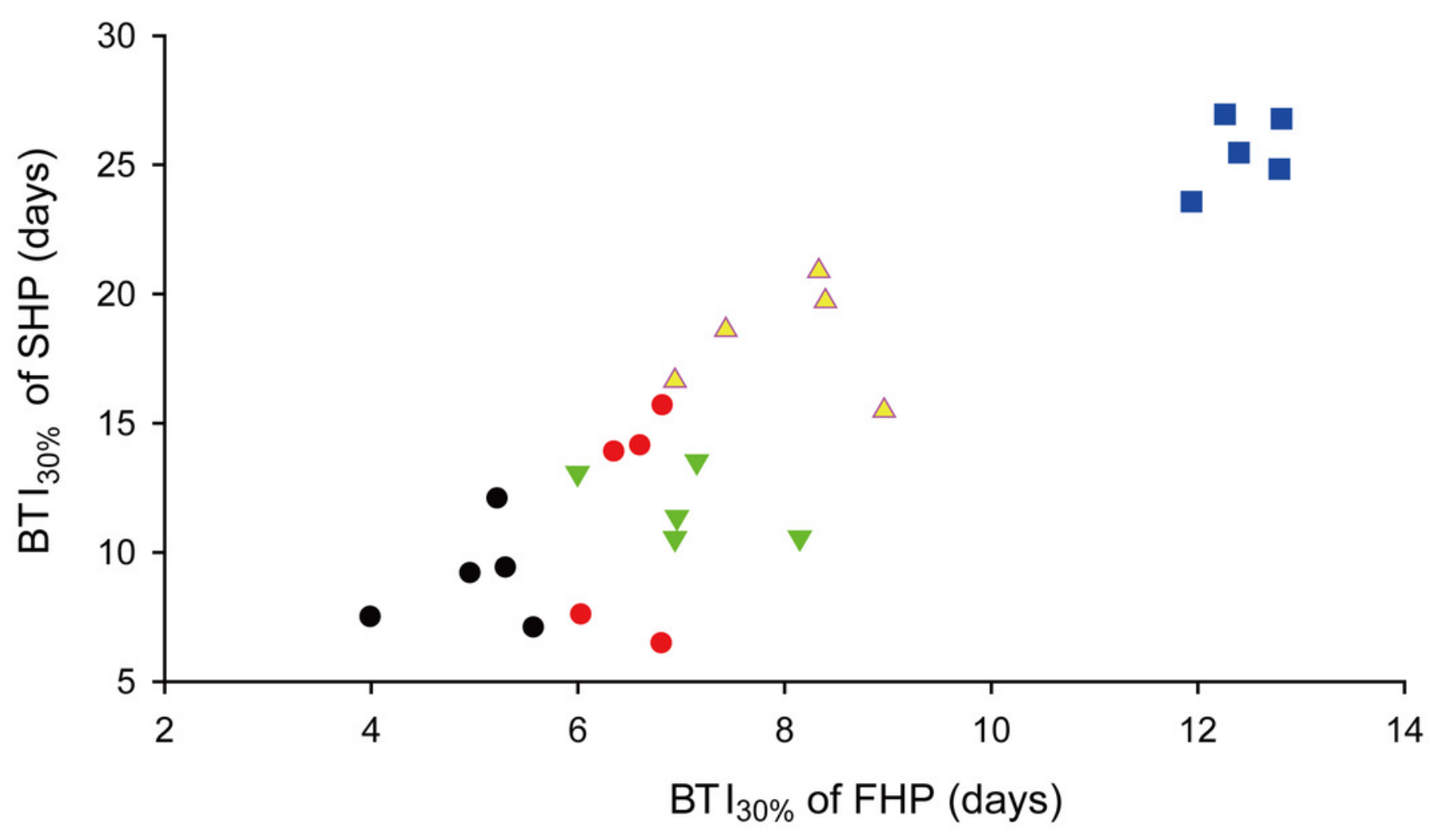




\section{Table $\mathbf{1}$ (on next page)}

Comparisons of imaging and algal cell-counting methods for quantifying coral bleaching among species 


\begin{tabular}{|c|c|c|}
\hline \multirow{2}{*}{$\begin{array}{l}\text { Requirements and } \\
\text { advantages }\end{array}$} & \multicolumn{2}{|c|}{ Methodology } \\
\hline & Counting algal cells (CZ) & $\begin{array}{c}\text { Photography image } \\
\text { (PI) }\end{array}$ \\
\hline Sampling area & $\begin{array}{l}\text { Hard to obtain accurate area, } \\
\text { especially for branching } \\
\text { corals. }\end{array}$ & $\begin{array}{l}\text { No need to calculate } \\
\text { sampling area. }\end{array}$ \\
\hline $\begin{array}{l}\text { Number of nubbins per } \\
\text { colony }\end{array}$ & $\begin{array}{l}\text { Number of nubbins per } \\
\text { colony needs to increases as } \\
\text { number of observations } \\
\text { increase from the beginning } \\
\text { of the experiment to the end } \\
\text { of bleaching. }\end{array}$ & $\begin{array}{l}\text { Same coral nubbins for } \\
\text { multiple times of non- } \\
\text { destructive photography. } \\
\text { Sample numbers could be } \\
\text { easily increased without } \\
\text { collecting more/larger } \\
\text { coral fragments. }\end{array}$ \\
\hline Equipment & $\begin{array}{l}\text { Water pick, centrifuge, } \\
\text { microscope, hemocytometer } \\
\text { etc. }\end{array}$ & $\begin{array}{l}\text { Camera, light, color card, } \\
\text { software, e.g., Photoshop } \\
\text { etc. }\end{array}$ \\
\hline Skills & Cell-biology training & $\begin{array}{l}\text { Digital photography } \\
\text { training }\end{array}$ \\
\hline Lab facility & $\begin{array}{l}\text { Proportionally larger space } \\
\text { according to: species } \\
\text { numbers, and numbers of } \\
\text { observation per spp. }\end{array}$ & $\begin{array}{l}\text { Proportionally larger space } \\
\text { according to species } \\
\text { numbers, only. }\end{array}$ \\
\hline Raw data & Y: Cell densities & $\mathrm{Y}: \%$ in grayscale \\
\hline Sampling assumptions & $\begin{array}{l}\text { Homogeneity among } \\
\text { nubbins within a colony in } \\
\text { cell numbers. }\end{array}$ & $\begin{array}{l}\text { No such assumption is } \\
\text { needed since the same } \\
\text { nubbins were observed } \\
\text { continually. }\end{array}$ \\
\hline Numbers of data point & $\begin{array}{l}\text { Constrained by the numbers } \\
\text { of nubbins available for } \\
\text { assay. }\end{array}$ & $\begin{array}{l}\text { Flexible; depending on } \\
\text { intervals between shots. }\end{array}$ \\
\hline $\begin{array}{l}\text { Numbers of species } \\
\text { compared } \\
\text { simultaneously. }\end{array}$ & Less & $\begin{array}{l}\text { More, we did } 5 \text { species } \\
\text { comparison in a } 300 \mathrm{~L} \\
\text { aquarium tank. }\end{array}$ \\
\hline
\end{tabular}


